${ }^{1}$ University of Canterbury, Aotearoa New Zealand

${ }^{2}$ Queensland University of Technology, Australia

${ }^{3}$ Flinders University, South Australia

\section{AOTEAROA}

NEW ZEALAND SOCIAL WORK 32(4), 26-39.

CORRESPONDENCE TO: Nik Taylor

nik.taylor@canterbury.ac.nz

\title{
Companion-animal-inclusive domestic violence practice: Implications for service delivery and social work
}

\author{
Nik Taylor ${ }^{1}$, Heather Fraser ${ }^{2}$ and Damien W. Riggs ${ }^{3}$
}

\begin{abstract}
INTRODUCTION: Based on an understanding of links between human- and animal-directed domestic violence, this article: 1) argues for companion-animal inclusive domestic violence service delivery; and 2) reflects on the challenges this offers to social work and the human services.
\end{abstract}

APPROACH: We start by considering the importance of companion animals in many people's lives and then offer an overview of material on "the link" between human- and animal-directed violence, specifically as it pertains to domestic violence.

CONCLUSIONS: Implications for service design and provision are discussed. We conclude with brief comments about the importance of centring animals in future considerations of humananimal violence links and outline how this offers an opportunity to challenge and re-think the humanist foundations on which traditional social work is built.

KEYWORDS: Companion animals; domestic violence; victims/survivors; service provision; social work

Domestic violence is a significant and potentially fatal social problem that has short- and long-term effects on individuals (Fraser \& Seymour, 2017). In Australia, more than one woman a week is killed by a male partner or ex-partner (Bryant \& Bricknall, 2017) and, in 2016, police conducted one family violence investigation every five minutes in Aotearoa (It's Not Ok, 2017). Seldom mentioned by the mainstream media but also often caught up in domestic violence are companion animals who experience similar kinds of physical and emotional abuse to humans (Taylor \& Fraser, 2019). In Aotearoa there are close to 5000 companion animals in $64 \%$ of households (Companion Animals in New Zealand (NZCAC), 2016) and an estimated 24 million companion animals in $62 \%$ of households in Australia
(RSPCA, 2019). These animals are mostly perceived of and treated as family members (Charles, 2016; Risley-Curtiss, Holley, \& Kodeine, 2011), not trivial adjuncts to the lives of humans. This leaves them open to abuse. It also means that they can be used against human victims of domestic violence, as seen in the fact that many humans experiencing domestic violence who live with companion animals, report remaining in abusive relationships or significantly delaying leaving, due to concern for their animals' well-being (Collins et al., 2018; Roguski, 2012; Taylor \& Fraser, 2019). This should put domestic violence against animals firmly in the purview of service provision.

In this article, the case is made for companion-animal-inclusive domestic 
violence service delivery. Implications for domestic violence service providers are given and programmatic considerations are discussed. We conclude the article by briefly discussing the implications this has for traditional social work that is built upon humanist assumptions (Ryan, 2011) and argue that it offers the discipline an opportunity to extend thinking about power, domination and control and thus contribute to important debates in critical and radical social work thinking. Throughout the piece we use images from the "Loving You, Loving Me: Companion Animals and Domestic Violence" project conducted throughout 2016-2017. This project aimed to investigate the meaning of companion animals to those fleeing domestic violence. Of particular importance to the current article was to at least partially include animals in the research process, achieved by asking participants to ensure their presence during interviews, and by offering all participants the opportunity to take part in a photo shoot where volunteers from a local photography club took images of participants and their animals. These images were gifted to the human participants to acknowledge their participation. In keeping with the arguments presented in this article and made more extensively throughout the Loving You project outputs, ensuring the animals affected by domestic violence were not invisible, or made visible solely through their human caretakers' accounts, was of paramount importance. Also important was the belief that images have the power to engage many in conversations about domestic violence and animal abuse who might otherwise turn away from such a difficult topic (see Taylor \& Fraser, 2019, for more details)

\section{Companion animals and human wellbeing}

People the world over have long indicated that animals play an important role as companions in their lives and families (Charles, 2016). Research highlights many positive benefits for humans that stem from this, and from broader aspects of animal interaction and companionship, including those related to:

a. daily assistance, for example, dogs assisting humans with visual impairment (Whitmarsh, 2005);

b. therapy, for example, animal assisted therapy (dogs, cats, horses, guinea pigs, chickens and so on) but also informal, family pet arrangements (Perkins, Bartlett, Travers, \& Rand, 2008; Taylor, Fraser, Signal, \& Prentice, 2014); and

c. physical and mental health, such as giving humans a sense of connection, purpose, and daily routines, many of which include physical exercise (see e.g., Ryan \& Ziebland, 2015).

Increasing recognition is now being given to the role that companion animals can play in reducing social isolation, increasing social connectedness and mental wellness among humans (see Fraser \& Taylor, 2017; Riggs, 2019). Animals can help humans connect-with other animals, with other humans, and with themselves. Humane education programmes for children, for example, have been shown to induce greater empathy for other animals that may extend to other humans (Arbour, Signal, $\&$ Taylor, 2009). Companion animals have been found to assuage loneliness and feelings of social isolation, so much so that they are considered by some to be 'social lubricants' who facilitate social interaction by providing "a shared focus of nonthreatening interaction between strangers or casual acquaintances" (Sanders, 1998, p. 11). Companion animals in particular can help humans feel loved especially during times when they may feel unlovable (Charles, 2014; Rhoades, Winetrobe, \& Rice, 2015; Taylor \& Fraser, 2019).

These benefits are particularly salient for many members of marginalised groups, 


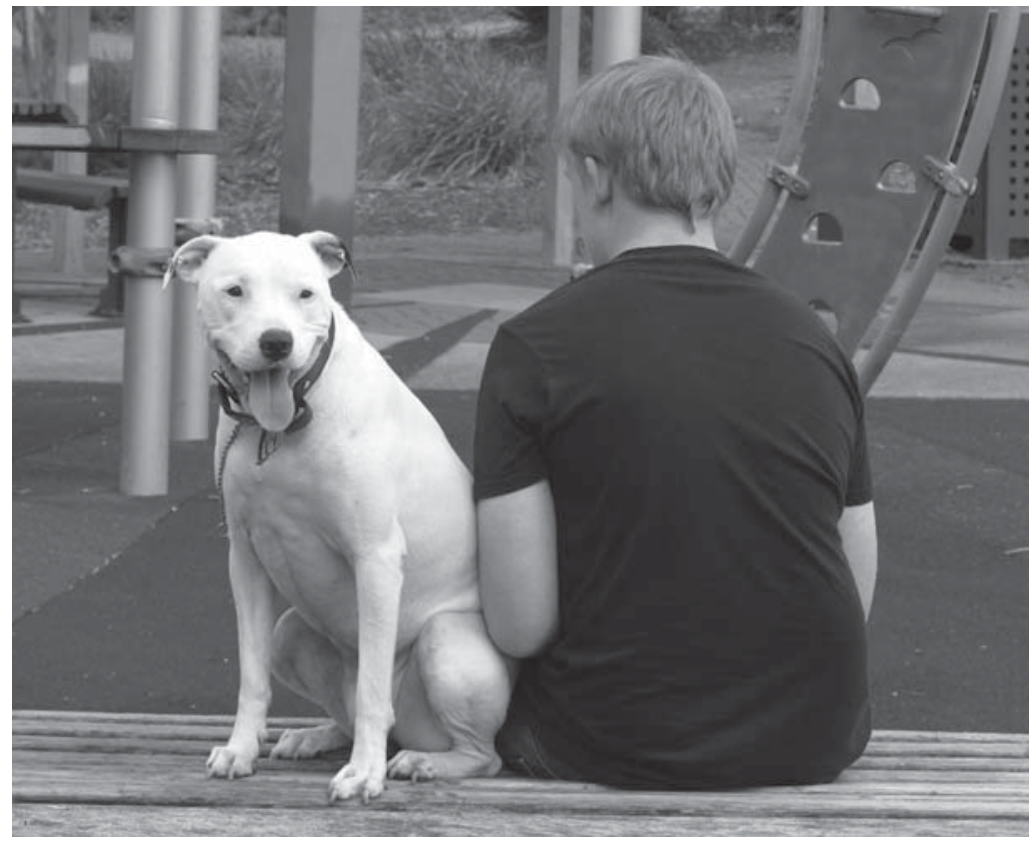

Image 1: "I've got your back" (Taylor \& Fraser, 2019), courtesy of Mawson Lakes Photography Club. also found that animal companionship can help mitigate LGBT+ people's experiences of discrimination and abuse and so contributed to improved health and wellbeing (Taylor et al., 2019).

Companion animals are non-judgmental, having no regard for human hierarchies or conventions relating to sex, gender, age, class or any other aspect of social status (Charles, 2014). Across diverse populations, companion animals offer many other potential benefits to human health and wellbeing. They can, for example, help some humans when they are lonely, unwell or managing an episode of a disorder (Smith, 2012). For example, early research demonstrated that newly widowed elderly companion animal owners had less frequency of minor ailments like headaches and tended to use less drugs during the period of bereavement than their counterparts without pets (Akiyama, Holtzman, \& Britz, 1987), and that companion animal attachment and depression were inversely related (Garrity, Stallones, Marx, \& Johnson, 1980). More recently, research has demonstrated that companion animals may help older women feel less lonely and depressed (KrauseParello, 2012). Rhoades et al. (2015) found that homeless young people with animals reported less depression and loneliness than non-animal-owning peers, in part because the animals offered company, reduced loneliness and made them feel loved. These connections and the unconditional support offered by other animals to some humans can be comparable to, and in some cases surpass, that offered by human-human relationships (see Bonas, McNicholas, \& Collis, 2000). This proximity to human family lives, however, leaves some companion animals open to abuse.

\section{The link(s) between human and animal abuse}

In recent decades there has been a greater recognition of "the link", or more accurately, "the links" between human and animal 
violence (Becker \& French, 2004; Flynn, 2012; Taylor \& Fraser, 2019). For instance, in one US study $65 \%$ of those arrested for crimes against animals had also been arrested for battery against humans (Degenhardt, 2005). In another, $1.8 \%$ of 43,093 people surveyed (extrapolated to equate to about 215 million Americans) admitted to animal cruelty. When compared to those who did not report animal cruelty, they were significantly more likely to have committed all 31 antisocial behaviours also measured. The strongest relationships were between committing animal cruelty and robbery/mugging, arson, harassment and threatening behaviour (Flynn, 2012).

Research demonstrates an even clearer link between animal abuse and other forms of family abuse (Flynn, 2012). Animal cruelty occurs more frequently in families where domestic/family violence is also occurring (for overview see Flynn, 2012; Taylor \& Fraser, 2019). Roguski (2012) surveyed 203 Women's Refuge clients in Aotearoa New Zealand (27.6\% Māori; 8.4\% Pasifika; 77.8\% NZ European) and found that $36.5 \%$ of respondents reported an animal had been harmed during their relationship, $11.8 \%$ reported that this occurred without any previous threats being made. Thirty-two percent of those who had children $(n=159)$ reported their children had witnessed threats to a family animal, and $24.5 \%$ had witnessed the animal being harmed or killed. Acts of animal cruelty in the home may also be an indication of violence perpetrated against elders or between siblings (Peak, Ascione, \& Doney, 2012).

Not only are animals important in identifying potential forms and occurrences of abuse, but bonds between humans and their companion animals have been shown to be crucial both during the abuse and to recovery post-abuse (e.g., Fitzgerald, 2005), partly because they may be the only positive relationship present in the abused person's life (Fitzgerald, 2007; Taylor \& Fraser, 2019). In some cases, human survivors talk about their animals being "life-savers" due to the emotional support they offer (Fitzgerald, 2007). For example, Flynn (2000), in his interviews with women who had experienced domestic violence along with their animals, found that the animals acted in the role of comforter after violent episodes, offering unconditional love. The women also suffered additional stress and guilt when having to leave their animals behind. Both of these findings are well documented elsewhere (for an overview see Taylor \& Fraser, 2019).

\section{Implications for domestic violence service providers}

Given that research shows that, for some human victims of domestic violence, having a bond with a companion animal can help them recover, we now consider some of the key implications of this for domestic violence service providers.

\section{Animal abuse often means increased violence against humans}

Domestic violence service providers are wise to take seriously reports of animal cruelty because domestic abusers who hurt animals also tend to use more extreme violence against humans (Barrett, Fitzgerald, Peirone, Stevenson, \& Cheung, 2018), with abusers who emotionally harm animals being the most likely to do so to exert power and control over their human victims (Fitzgerald et al., 2019).

\section{Human-animal bonds can intensify through shared experiences of violence}

Companion animals are an important and often underestimated source of support for many (human) domestic violence victims (Fitzgerald, 2007; Flynn, 2000; Taylor \& Fraser, 2019). Research has shown us that, in violent households comprising of both human and animal family members, relationships between humans and animals may intensify in meaning, and provide crucial forms of support and comfort (Fitzgerald, 2007; Flynn, 2000). Image 2, 


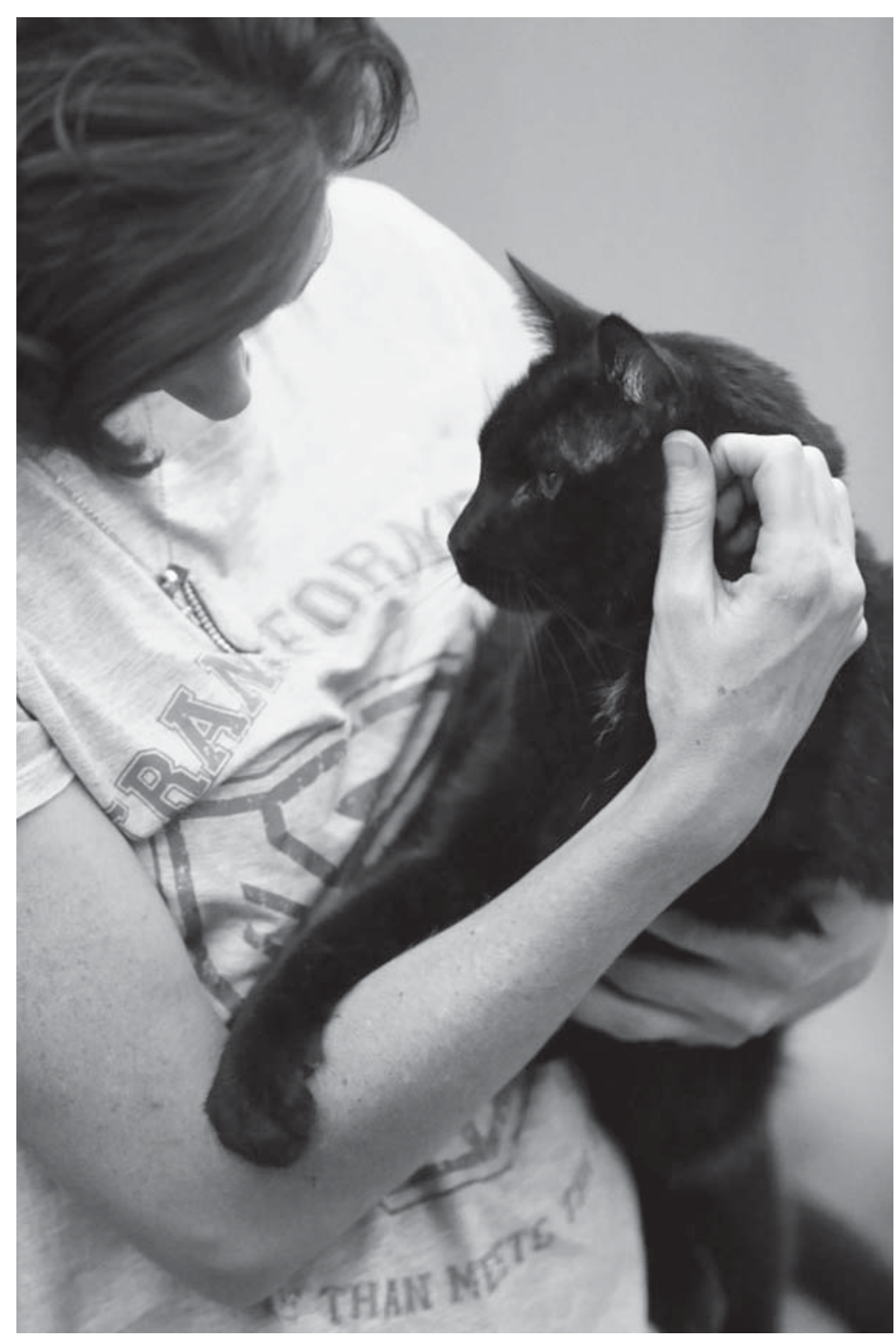

Image 2: "My world" (Taylor \& Fraser, 2019), courtesy of Mawson Lakes Photography Club. domestic violence have shown similarly (Fraser et al., 2019; Taylor et al., 2019).

Victims/survivors unwilling to leave without pets

It is now well-established that one factor preventing many victims / survivors of domestic violence from seeking help is unwillingness to leave companion animals with perpetrators (Ascione et al., 2007; Barrett et al., 2018; Flynn, 2000; Taylor \& Fraser, 2019). For example, Barrett et al. (2018) found that concern over companion animals often contributes to a woman's decision to return to her abuser after having initially severed the relationship.

\section{Supporting companion animals can assist human victims}

Many people, especially people from marginalised groups, find talking about and sharing photographs of companion animals to be a pleasurable experience, and often a source of great pride (Fraser, Bartholomaeus, Riggs, Taylor, \& Rosenberg, 2019). Workers are more likely to establish rapport with victims if they take an interest in both human and animal relationships that victims' report as important (Fraser et al., 2019), so much so that animals can be "conduits to social work assessment" (Evans \& Gray, 2012, p. 603; Papazian, 2014). Discussion of companion animals and their exposure to violence can become a bridge into human experience (Fraser, Beddoe, \& Ballantyne, 2017; Fraser, Taylor, \& Morley, 2017). This can be particularly important with groups who may not respond well to social workers initially for any variety of reasons. RisleyCurtiss et al. (2011), for example, suggested that social workers working with boys and / or men, might incorporate questions about animals routinely as it is perceived as less threatening, and is a way to establish rapport.

Conversely, ignoring animals in social work practice might hinder workers' abilities to help their clients. Risley-Curtiss (2013, p. 126) 
argued that ignoring animals in child welfare practice "can shortchange our abilities to help clients" in numerous ways. These include failing to include family-centred assessments, failing or slowing the chance to recognise problem behaviours such as animal abuse and domestic violence and thereby limit options for early intervention, failing to recognise and promote potential healing and resiliency relationships with other animals, and failure to validate important family members (i.e., the animals). Ignoring the roles other animals play in families may also mean ignoring their potential to help their humans in previously unconsidered ways. For example, in relation to LGBT+ people's experiences, Taylor et al. (2019) found that some human victims will seek help when the abuse against their animals escalates (rather than when it escalates for themselves). Service providers are wise to take seriously both the love victims can feel for their animals, and their concerns about experiences of abuse and possibilities of recovery in the future (Fraser et al., 2019).

Service providers who consider companion animals in their service design and operations, marketing material and staffing arrangements may have increased chances of reaching clients when they are in danger, hurt and abused (Fraser et al., 2019). Volant, Johnson, Gullone, and Coleman (2008) found that the positive identification of at-risk members of the community (both human and animal) by community professionals (i.e., vets, animal welfare agents, police, child welfare agents, counsellors) promises to enable the negative consequences of animal abuse and domestic violence to be addressed more effectively.

\section{Benefits of human and animal victims/ survivors recovering together}

Human victims are right to be concerned about the animals that they love and do not want to leave behind with perpetrators. Apart from the ongoing abuse and neglect, if not escalation of abuse that many animals will face post-separation, there are also other similarly dire possibilities: animals running away and being hurt or killed in the process; animals being surrendered or abandoned, left in animal shelters that cannot secure enough homes for them to go to; shelters often face euthanising otherwise healthy animals (Flynn, 2000; Taylor \& Fraser, 2019). For both human and animal survivors of domestic violence, including the many who suffer post-traumatic stress from their experiences of violence, there are many possible health benefits of remaining together through common processes such as escape, relocation and recovery (Krause-Parello, Sarni \& Padden, 2016; Taylor, Edwards, \& Pooley, 2013). Before, during and after violent episodes, animal and human victims can provide each other with a sense of protection, solace, love and loyalty. Service delivery that takes into account the needs of those with companion animals-as well as, potentially, the needs of the animals themselves-is therefore beneficial. In the next section we consider some of the ways in which services might be able to consider including and / or helping animals.

\section{Animal-inclusive service delivery design}

Offering animal-inclusive and / or centred services is not without its challenges. RisleyCurtiss (2013) lists the following barriers to including animal-human relations into child welfare practice: 1 ) speciesism, "dismissing animals and the importance they have in the lives of humans" (p. 121) due to the anthropocentrism of the human and social services. To this we would add the existence of a hierarchy of caring, one that indicates caring about people is more important than, and antecedent to, caring about animals. As Adams argues, this is an inherently dangerous idea, given that " [m] any of the arguments that separate caring into deserving / underserving or now / later or first those like us / then those like us constitute a politics of the dismissive" (Adams, 2016, p. 5); 2) administration 
whereby speciesism manifests in the refusal to incorporate animal-centred practices;

3) computerised case management that leads, for example, to risk assessments being copyrighted and ensures that any changes made are extremely slow; 4) confidentiality that makes cross-reporting initiatives (between human and animal services) difficult and time consuming; 5) lack of knowledge at both the practice level and within social work and human services undergraduate training programmes; and, 6) lack of staff and time (Risley-Curtiss, 2013, pp. 120-124).

Despite these difficulties, however, there has been an increase of services that attend to domestic violence faced by human and animal victims often through temporary fostering services such as those offered through Pet Refuge NZ (https: / / www. petrefuge.org.nz/) and Safe Pets, Safe Families (https: / / safepetssafefamilies. org.au/). Fewer services offer housing for human domestic violence victims that allow companion animals to stay with them although they are increasing. In Australia, the Northern Domestic Violence Service (NDVS) in South Australia has animalfriendly housing for instance and client feedback has been extremely positive, with several indicating that they would not have reached out for help if this option had not been available (Taylor \& Fraser, 2019). Throughout 2016, two of the authors of this article worked closely with NDVS on a research project aimed at understanding the importance of animal-friendly housing (Taylor \& Fraser, 2019). Below are some of the insights we gleaned during this project.

\section{Staff need to be willing to champion the importance of human-animal bonds}

Recognising the significance of animal companionship, writing it into policies and procedures and helping to operationalise services that are animal-inclusive, can take time and expertise, but most importantly, the will to do so. Each agency or branch of an organisation is likely to need people willing to champion the idea of an animal-friendly service and help make it happen.

Domestic violence services are often well placed to move to, or extend, their animal-inclusive service delivery design given they are predominantly provided by women, many of whom care about and, most importantly, advocate for animals. Even those staff who are not particularly interested in other animals are often well placed to understand the ethics and practices associated with animals being victims of domestic violence given both forms of violence (to humans and animals) are based on power and control. From this general support, individuals may take up specific roles to advance the work. They may also provide support to other services regarding what animal-friendly will mean and how it will be operationalised. Liaising with animal protection agencies and related others may be part of the roles directly tied to helping make animal-friendly service delivery a success. As Fitzgerald, Barrett, Stevenson, and Cheung (2019, p. 2) note:

Specifying the factors that increase the probability of pet abuse is critical to inform the development of risk assessment measures that can identify pets that may be in elevated danger, as well as people who are being victimised and whose decision making regarding leaving the relationship may be shaped by the abuse of their pet(s). Such knowledge can be used by organizations and/ or practitioners engaging in safety planning with survivors to promote the safety of not only women and children but also their pets, as research indicates that fear for the safety of pets may delay a woman's decision to leave an abusive relationship ... Therefore, promoting the safety of pets is critical not only for the well-being of animals but also for the protection of the people who care for them.

Physically accommodating animals and associated requirements 
While temporary foster care arrangements for animal victims of domestic violence offer an important avenue, many victims would do better staying together. Human victims, for example, often report that separation from their animals leads to guilt and loneliness (Flynn, 2000), while animal victims often suffer separation anxiety and potential behavioural issues as a result of forced separation (Taylor \& Fraser, 2019). Keeping human and animal victims of domestic violence together usually necessitates the physical redesign of housing arrangements to accommodate animals without jeopardising the safety of other residents. Appreciating the important role humans and animals can play in their shared recovery from domestic violence, therefore, has resourcing implications for organisations. Physically accommodating animals is likely to add costs to the budget, particularly if emergency animal supplies are to be made available, and if some leeway is to be given to the potential damage of furniture by resident animals. These issues are exacerbated considerably if the animals in question are numerous, very large and / or species other than cats, dogs and small rodents / birds.

Caring for pets who are also recovering from exposure to violence

Most animals brought into supported accommodation will have been exposed to emotional and/ or physical abuse, if not directly targeted. This abuse may have been occurring for many months if not years. Growing numbers of studies are showing how animals can exhibit similar reactions to violence as humans (anxiety, depression, hyper vigilance, acting out etc.) (see Taylor \& Fraser, 2019, for an overview). Recognising animals as victims of violence in their own right can help to ensure that their welfare is not neglected. As with humans, animals will also need time and space to recover from the trauma of violence. Care is needed to ensure the safety of the animals in residence but also the other humans around them (staff, other residents, visitors). Young children will ordinarily need to be supervised around animals to prevent them from being rough with animals or re-enacting animal cruelty, which can evoke animal aggression-fear based or otherwise. It is important to note that whether young or old, human survivors of domestic violence are often good to animals-but not always (Riggs, Taylor, Signal, \& Donovan, 2018). Also, some people will be so traumatised that they will need support to provide the daily care that animals need. Without this support, animals risk further neglect and harm. For the relatively small numbers of victims / survivors who find caring for their animals too overwhelming not just in the present but in the foreseeable future, foster care arrangements, or adoption of the animals, may be necessary.

\section{Creating and updating pet policies and procedures}

Necessary parts of animal-inclusive service delivery design are the policies and procedures designed to protect the safety and wellbeing of all in residence, including staff and visitors. To have achieved some of the work described above, policies and procedures are necessary. In plain language they will outline the expectations of humane treatment of animals (for example, positive training techniques to correct animal behaviour and other RSPCA-endorsed methods), and the kinds of behaviours that the animals will be expected to display or be taught (for instance, wearing collars with identification and being kept in their own yard unless being walked with a human).

In addition to creating policies aimed at protecting the animals present in companion-animal friendly services, policies, clear processes and support are needed for staff willing and able to work in this area. Seemingly few human and social services have formal policies in place to address animal abuse. Stevenson, Fitzgerald, and Barrett (2018), in their survey of 116 
domestic violence shelter staff from 40 shelters across Canada reported that $25.9 \%$ of responders stated they had no policy and no services for animals. The most common kind of service reported offered was referral to another community group that could help (46.6\%), boarding at the local kennels $(43.1 \%)$, foster care $(12.9 \%)$ and boarding at a local vets $(8.6 \%)$. This lack of formal policy adds stress to workers trying to help families in violent situations. MontminyDana (2007), in a study investigating the experiences of child welfare workers assigned child maltreatment cases where animal abuse was also present found that all of their participants who reported on cases where both forms of abuse were present indicated they were the most challenging to deal with (p. 92). Moreover, as a result of the lack of formal policies and directives, they began developing their own best practices regarding how to intervene in cases where animal abuse was present. These included the removal of animals into safer, alternate, places such as animal shelters and / or into foster care. Laing (2019), in her study of the ways Australian social workers work creatively and/or subversively to develop animal-inclusive practices, also documents that many social workers take animals in need to their own homes and / or withhold information from colleagues or other services about the presence of other animals so they would not be intentionally excluded.

Taken together this suggests the urgent need for social workers and human service professionals regarding the importance of recognising and addressing animal cruelty.

\section{Training and development}

Professional development for staff and community education regarding the importance of human-animal relationships for many child and adult victims of domestic violence will also be needed, as will training about the necessity of including information about animals in risk assessments (Humphrey, 2002; Walker, Aimers, \& Perry, 2015). The workers in Montminy-Dana's study (2007) suggested that mandatory training should be provided to both current and new staff. They indicated this training should involve: 1) an overview of animal cruelty; 2) the connections between animal cruelty and family violence; and 3) issues pertaining to methods of assessment and treatment (pp. 92-93). Other suggestions for moving forward included the need to make workers aware of existing resources addressing the complexity of human-animal abuse and the needs of families in these situations; establishing groups for animal abusers, especially relevant where children are the perpetrators; including assessment measures in formal processes such as having the initial human services contact ask about companion animals, and adding questions to intake forms that are designed to elicit information about behaviours toward any current and/or past companion animals. This call for more information is echoed by Randour (2007) who further noted the need to employ consistent terminology across any attempts to collect data about animal abuse.

Research into human-animal abuse links has grown considerably over the last two decades or so and, as part of this, there is more awareness and more information upon which to base training. As a result, training opportunities are increasing but still seem to be far from mandatory. For instance, Stevenson et al. (2018) in their survey of 40 shelters across Canada reported that $37.7 \%$ of respondents indicated their training had no animal abuse content. Some $36 \%$ stated that there was a "brief mention" of animal abuse in their training and $19.3 \%$ indicated their training included a "short discussion" of animal abuse.

From the intersecting fields of domestic violence, aged care, child welfare, poverty relief, homelessness and corrections, more people are sharing stories of new initiatives and experiences with some form of petinclusive service design (see for example, Lynch, 2017; Reading Buddies, 2019). As Randour (2007) noted, the development of services aimed at helping animal 
victims of domestic violence indicate that practitioners readily recognise the importance of animals in family dynamics. Given this awareness, any training initiatives are likely to be well received.

This training also needs to occur in human services and social work curricula (see Risley-Curtiss, 2010) and could involve, for instance, instituting social work student placements at animal rescue organisations. One report of a successful example of this notes that social work students placed in shelters can offer numerous skills such as developing and implementing support animals in community services; addressing compassion fatigue among the shelter staff; raising community awareness regarding links between human- and animal-directed violence (Hoy-Gerlach, Delgardo, Sloane, \& Arkow, 2019). The authors concluded that the Humane Society, while being a non-traditional setting for a social work placement, offered an environment eminently suitable for the development of social work skills. At the same time, the placement allowed shelter staff who initially did not understand how a social worker might fit at their workplace, to recognise the value of a social worker, so much so they were eager for the placements to continue. As human-animal studies courses begin to grow, it will be worth considering whether relevant students can be placed in domestic violence service provision in order to continue the kind of cross-pollination of information identified by Hoy-Gerlach et al. (2019) as useful for social work students. Similarly, the inclusion of animal-centred issues in human services and social work curriculums offer many opportunities, not least of which, as Adamson and Darroch (2016, p. 41) point out, is "an opportunity to highlight what is an under-explored element of human experience within social work education - that of the human-animal bond and its implications for social work intervention." In their reflection on embedding animalcentred issues into a social work class through focussing on animals in disasters and animals in domestic violence, they also noted that such approaches offered the possibility of forging new theoretical connections between existing student knowledge and "practice realities" (p. 46).

\section{Associated activities}

Beyond the need for formal training and policies, there are numerous activities those in the social work and human service professions can, and do, engage in to promote animal-friendly services.

These include:

- $\quad$ advertising on websites and social media platforms the inclusion of pets in some parts of the service;

- $\quad$ asking about pets from initial inquiries made about crisis support;

- counting pets that accompany clients into new housing arrangements;

- $\quad$ liaising directly with animal foster carers, animal control officers, police and / or the RSPCA to help reunite lost animals or animals still in crisis at home;

- $\quad$ supporting clients to access veterinary care for their pets, and council registration, including, microchipping and desexing;

- teaching staff and other residents how to interact-or avoid interacting - with animals in neighbouring units;

- $\quad$ fundraising and applying for grants related to pets that help sustain the budget; and

- $\quad$ partnering with researchers to (further) examine the benefits and challenges of a pet-inclusive service design. 


\section{Resistance and change}

The above recommendations are not unproblematic and they will inevitably face resistance from some quarters. Stevenson et al. $(2018$, p. 242) reported that the domestic violence shelter workers they talked to included the following reasons for lack of animal-friendly policies: 1) staff and/or resident allergies; 2) lack of funds; 3 ) lack of physical space; 4) hygiene concerns and/or concerns over property maintenance; 5) lack of community partnerships; and 6) safety concerns. These are valid considerations and need to be included in considerations of the development of animal-friendly domestic violence services and policies. However, they are not necessarily insurmountable barriers. For instance, Stevenson et al. (2018) reported that only 6 of their 116 respondents indicated that staff resistance was a reason for the absence of animal-friendly policy development.

One of the main reasons animalfriendly practices may face resistance is entrenched speciesism and associated anthropocentrism (Risley-Curtiss 2013). And, while these are structural issues that are difficult to counter, it is worth noting that we are beginning to see the seeds of change. For example, due to an expanded ecological consciousness social work is experiencing challenges and opportunities such as 'green social work' and 'veterinary social work' (see Boetto, 2017; Dominelli, 2012). Many of those advocating such a shift in social work argue that a significant barrier to the adoption of social work practices that include other animals is the discipline's reliance on positivist and modernist roots that are embroiled in maintaining the status quo vis-à-vis power relations (Boetto, 2017, p. 49). As Bell (2012) argued, uncritical adoption of traditional post-enlightenment, positivist paradigms that are grounded in notions of rationality leaves unchallenged the dualistic and hierarchical frameworks that we know from radical social work traditions must be removed if we are to meet the social justice aims of the discipline (Fraser et al. 2017). Leaving such frameworks intact is problematic, not least because it gives epistemic privilege to a certain masculinist perspective wherein the "perspectives of 'others' are either excluded entirely, incorporated as pathological and atypical according to the male-as-standard yardstick and/or have interpretive frameworks imposed on them regardless of fit" (Bell, 2012, p. 413). While the majority of those espousing arguments like this acknowledge the roles that these ideologies play in excluding both the environment and marginalised humans, they often fall short of acknowledging that this also ignores other (nonhuman) animals. There is a need, then, to further develop this line of critique to address how it pertains to other animals generally and to those animals who are domestic violence victims specifically.

In closing, we would like to reiterate that animals are victims of domestic violence in and of themselves. Throughout this article, we have deliberately used the phrase human and animal victims of domestic violence. We have done this to make clear that animal-friendly practices need to also consider centring the experiences of other animals. This means, in the context of domestic violence service provision, moving beyond the idea that acknowledging animal abuse within family dynamics as important only because it serves as a red flag for interhuman abuse. Instead, it means acknowledging that animals are sentient beings whose own experiences of physical and emotional abuse is worthy of attention and redress.

Accepted 5 May 2020

Published 15 December 2020

\section{References}

Adams, C. (2016). The Carol J Adams reader. Bloomsbury. Adamson, C., \& Darroch, J. (2016). When Ida came to class: The inclusion of animals in the social work curriculum. [online]. Advances in Social Work and Welfare Education, 18(2), 39-51. 
Akiyama, H., Holtzman, J. M., \& Britz, W. E. (1987). Pet ownership and health status during bereavement. OMEGA-Journal of Death and Dying, 17(2), 187-193.

Arbour, R., Signal, T., \& Taylor, N. (2009). Teaching kindness: The promise of humane education. Society and Animals, 17(2), 136-148.

Ascione, F. R., Weber, C. V., Thompson, T. M., Heath, J., Maruyama, M., \& Hayashi, K. (2007). Battered pets and domestic violence: Animal abuse reported by women experiencing intimate violence and by nonabused women. Violence Against Women, 13(4), 354-373.

Barrett, B., Fitzgerald, A., Peirone, A., Stevenson, R., \& Cheung, C. H. (2018). Helpseeking among abused women with pets: Evidence from a Canadian sample. Violence and Victims, 33, 604-626.

Becker, F., \& French, L. (2004). Making the links: Child abuse, animal cruelty and domestic violence. Child Abuse Review: Journal of the British Association for the Study and Prevention of Child Abuse and Neglect, 13(6), 399-414.

Bell, K. (2012). Towards a post-conventional philosophical base for social work. British Journal of Social Work 42(3), 408-423.

Boetto, H. (2017). A transformative eco-social model: Challenging modernist assumptions in social work. British Journal of Social Work, 47, 48-67.

Bonas, S., McNicholas, J., \& Collis, G. (2000). Pets in the network of family relationships: An empirical study. In A. Podberscek, E. Paul, \& J. Serpell (Eds.), Companion animals and us: Exploring the relationships between people and pets (pp. 209-236). Cambridge University Press.

Bryant, W., \& Bricknall, S. (2017). Homicide in Australia 2012-2014: National Homicide Monitoring Program report. Canberra, ACT: Australian Institute of Criminology. Retrieved from https://aic.gov.au/ publications/sr/sr002

Charles, N. (2014). "Animals just love you as you are": Experiencing kinship across the species barrier. Sociology, 48(4), 715-730

Charles, N. (2016). Post-human families? Dog-human relations in the domestic sphere. Sociological Research Online 21(3), 1-12.

Collins, E., Cody, A., MacDonald, S., Nicotera, N., Ascione, F., \& Williams, J. (2018). A template analysis of intimate partner violence survivors' experiences of animal maltreatment: Implications for safety planning and intervention. Violence Against Women, 24(4), 452-476.

Companion Animals in New Zealand (NZCAC). (2016). The New Zealand Companion Animal Council, Inc. Retrieved from https://www.nzvna.org.nz/site/nzvna/ files/Documents/Companionper cent20Animals_in_New_ Zealand_2016_Report_web.pdf

Cronley, C., Strand, E., Patterson, D., \& Gwaltney, S (2009). Homeless people who are animal caretakers: A comparative study. Psychological Reports, 105(2), 481-499.

Degenhardt, B. (2005). Statistical summary of offenders charged with crimes against companion animals. July 2001-July 2004. Animal Abuse Control Team. Chicago, IL: Chicago Police Department.
Dominelli, L. (2012). Green social work: From environmental crises to environmental justice. Polity.

Evans, N., \& Gray, C. (2012). The practice and ethics of animal-assisted therapy with children and young people: Is it enough that we don't eat our co-workers? The British Journal of Social Work, 42(4), 600-617.

Faver, C. A., \& Strand, E. B. (2007). Fear, guilt, and grief: Harm to pets and the emotional abuse of women. Journal of Emotional Abuse, 7(1), 51-70.

Fitzgerald, A. (2005). Animal abuse and family violence: Researching the interrelationships of abusive power. Edwin Mellen.

Fitzgerald, A. (2007). "They gave me a reason to live": The protective effects of companion animals on the suicidality of abused women. Humanity \& Society, 31, 355-378.

Fitzgerald, A., Barrett, B., Stevenson, R., \& Cheung, C. (2019). Animal maltreatment in the context of intimate partner violence: A manifestation of power and control? Violence Against Women [online first] doi:10.1177/1077801218824993

Flynn, C. (2012). Understanding animal abuse: A sociological perspective. Lantern Books.

Flynn, C. (2000). Woman's best friend: Pet abuse and the role of companion animals in the lives of battered women. Violence Against Women, 6, 162-177.

Fraser, H., Bartholomaeus, C., Riggs, D., Taylor, N., \& Rosenberg, S. (2019). Service provider recognition of trans and cisgender women of diverse sexualities, and the significance of animal companionship. Culture, Health and Sexuality, 22(1), 16-30.

Fraser, H., Beddoe, L., \& Ballantyne, N. (2017). Editorial: Is there a renaissance of radical social work? Aotearoa New Zealand Social Work, 29(2), 1-5.

Fraser, H., \& Seymour, K. (2017). Understanding violence and abuse: An anti-oppressive practice perspective. Fernwood Press.

Fraser, H., \& Taylor, N. (2017). In good company: Women, companion animals and social work. Society \& Animals, 25(4), 341-361.

Fraser, H., Taylor, N., \& Morley, C. (2017). Social work and interspecies care: An intersectional perspective on ethics, principles and practices. In B. Pease (Ed.), The politics of caring: Towards a critical ethic of care in social work (pp. 229-240). Routledge.

Garrity, T. F., Stallones, L., Marx, M. B., \& Johnson, T. P. (1989). Pet ownership and attachment as supportive factors in the health of the elderly. Anthrozoos, 3, 35-44.

Hoy-Gerlach, J., Delgado, M., Sloane, H., Arkow, P. (2019). Rediscovering connections between animal welfare and human welfare: Creating social work internships at a humane society. Journal of Social Work, 19(2), 216-232.

Humphrey, B. (2002). Child welfare, animal welfare - strengthening the links. Social Work Now, 4-9 (December)

It's Not OK. (2017). Family violence: It's not OK [infographic]. Retrieved from http://www.areyouok.org.nz/assets/ Uploads/Infographic-Poster-2017-2.pdf

Krause-Parello, C.A. (2012). Pet ownership and older women: The relationships among loneliness, pet attachment support, human social support, and depressed mood. Geriatric Nursing, 33(3), 194-203. 
Krause-Parello, C. A., Sarni, S., \& Padden, E. (2016). Military veterans and canine assistance for post-traumatic stress disorder: A narrative review of the literature. Nurse Education Today, 47, 43-50.

Laing, M. (2019, July). Encountering interspecies homelessness: Subversively smashing anthropocentrism in social work and the all-too-human services. Paper presented at Decolonising Animals: Australasian Animal Studies Conference, Christchurch, Aotearoa New Zealand.

Lynch, J. (2017). Greyhounds go behind bars to learn how to become pets, teach prisoners responsibilities, ABC News South West WA. Retrieved from https:// www.abc.net.au/news/2017-07-09/greyhoundsas-pets-program-benefits-bunbury-prisoners-anddogs/8689346

Montminy-Danna, M. (2007). Child welfare and animal cruelty: A survey of child welfare workers, Journal of Emotional Abuse, 73, 83-96.

Papazian, N. (2014). No one ever asked me that: The value of social work inquiry into the human-animal bond. In $\mathrm{T}$. Ryan (Ed.), Animals in Social Work: Why and How they Matter (pp. 167-180). Palgrave.

Peak, T., Ascione, F., \& Doney, J. (2012). Adult protective services and animal welfare: should animal abuse and neglect be assessed during adult protective services screening? Journal of Elder Abuse \& Neglect, 24(1), 37-49.

Perkins, J., Bartlett, H., Travers, C., \& Rand, J. (2008). Dog-assisted therapy for older people with dementia: A review. Australasian Journal on Ageing, 27, 177-182.

Randour, M. L. (2007). Integrating animals into the family violence paradigm: Implications for policy and professional standards. Journal of Emotional Abuse, 7(3), 97-116.

Reading Buddies (North Shore, NSW). (2019). About reading buddies. Retrieved from https://www.k9readingbuddies. org/about/

Rhoades, H., Winetrobe, H., \& Rice, E. (2015). Pet ownership among homeless youth: Associations with mental health, service utilization and housing status. Child Psychiatry and Human Development, 46(2), 237-244.

Riggs, D. W. (2019). Working with transgender young people and their families: A critical developmental approach. Palgrave Macmillan.

Riggs, D.W., Taylor, N., Signal, T., Fraser, H., \& Donovan, C. (2018). People of diverse genders and/or sexualities and their animal companions: Experiences of family violence in a bi-national sample. Journal of Family Issues, 39, 4226-4247.

Risley-Curtiss, C. (2010). Social work and other animals: Living up to ecological practice. In M. DeMello (Ed.), Teaching the animal: Human-animal studies across the disciplines (pp. 281-298). Lantern Books.

Risley-Curtiss, C. (2013). Expanding the ecological lens in child welfare practice to include other animals. Journal of Sociology \& Social Welfare, 40(4), 107-130.

Risley-Curtiss, C., Holley, L. C., \& Kodeine, S. (2011). "They're there for you": Men's relationships with companion animals. Families in Society: The Journal of Contemporary Social Services, 92(4), 1-7.
Roguski, M. (2012). Pets as pawns: The co-existence of animal cruelty and family violence. Report to RNZSPCA and The National Collective of Independent Women's Refuges.

RSPCA. (2019). How many pets are there in Australia? Retrieved from https://kb.rspca.org.au/knowledge-base/ how-many-pets-are-there-in-australia/

Ryan, S., \& Ziebland, S. (2015). On interviewing people with pets: Reflections from qualitative research on people with long-term conditions. Sociology of Health \& IIIness, 37(1), 67-80.

Ryan, T. (2011). Animals and social work: A moral introduction. Palgrave Macmillan.

Sanders. C. (1998). The canine-human "with": Dogs, people and public interaction. International Society for Anthrozoology Newsletter, 16, 11-15.

Smith, B. (2012). The "pet effect": Health related aspects of companion animal ownership. Australian Family Physician, 41(6), 439=442.

Stevenson, R., Fitzgerald, A., \& Barrett, B. J. (2018). Keeping pets safe in the context of intimate partner violence: Insights from domestic violence shelter staff in Canada. Affilia: Journal of Women and Social Work, 33(2), 236-252.

Taylor, M. F., Edwards, M. E., \& Pooley, J. A. (2013). "Nudging them back to reality": Toward a growing public acceptance of the role dogs fulfill in ameliorating contemporary veterans' PTSD symptoms. Anthrozoös, 26(4), 593-611.

Taylor, N., \& Fraser, H. (2019). Rescuing you, rescuing me: Domestic violence and companion animals. Palgrave.

Taylor, N., Fraser, H., Signal, T., \& Prentice, K. (2014). Social work, animals and ethics: A case study of an animal assisted therapy program for child sex abuse victims. British Journal of Social Work, 46(1), 135-152.

Taylor, N., Riggs, D. W., Donovan, C., Signal, T., \& Fraser, $H$. (2019). People of diverse genders and/or sexualities caring for and protecting animal companions in the context of domestic violence. Violence Against Women, 25(9), 1096-1115

Volant, A. M., Johnson, J. A., Gullone, E., \& Coleman, G. J. (2008). The relationship between domestic violence and animal abuse: An Australian study. Journal of Interpersonal Violence, 23, 1277-1295.

Walker, P., Aimers, J., \& Perry, C. (2015). Animals and social work: An emerging field of practice for Aotearoa New Zealand. Aotearoa New Zealand Social Work, 27(1\&2), 24-35.

Whitmarsh, L. (2005). The benefits of guide dog ownership. Visual Impairment Research, 7(1), 27-42. 


\section{Appendix}

Pet-inclusive training and information opportunities can be fun, uplifting and inspiring for staff and residents, and useful content is freely available on many platforms (videos, posts, blogs, news reports and so on). For instance, people might start by exploring the following websites:

Lucy's Project https: / / lucysproject. com/

My Saving Grace http://www. mysavinggrace.org.au/

Safe Kennels RSPCA

https: / / www.rspcasa. org.au/safe-kennelsproject/

Safe Families, Safe Pets

https: / / safepetssafefamilies. org.au/

National Link Coalition

http: / / www. nationallinkcoalition. org/

Delta Therapy Dogs

https: / / www. deltasociety.com.au/ delta-therapy-dogs

First Strike http: / / www. scottishspca.org/ campaigns / 43_firststrike

The Links Group (UK)

http: / / www. thelinksgroup.org.uk/ index.htm

One of the Family (NZ)

http: / / rnzspca.org.nz / education/ one-of-thefamily 